\title{
Construction on "Cooperation - Discovery - Successful" Three-dimensional Model in College Aerobics Courses
}

\author{
Ying Zhang \\ School of Education and Sports, Bohai University, Jinzhou, P.R. China \\ 47086132@qq.com
}

Keywords: Aerobics courses; cooperation; discovery; successful; three-dimensional model

\begin{abstract}
Aerobics courses are an important part of college athletics curriculum system, is a athletics loved by students, it has multi-faceted, multi-level didactical function. In this study, based on the in-depth understanding of the drawbacks of our college traditional aerobics learning model development proposed cooperative learning model, discovery learning mode, successful learning mode, meanwhile introducing conception of college athletics programs, respectively from a theoretical basis, achieving objectives, the program flow, system evaluation and other aspects to create a new development strategies for three-dimensional learning model, the aim is to promote reform for our college movement courses, to provide theoretical basis and practical reference for promoting sustainable and healthy development for aerobics learning .
\end{abstract}

\section{Introduction}

Modern society is a society of competition and cooperation, not only needs the sense of competition, but also needs the spirit of cooperation. in 1996, the International 21st Century Educational Committee submitted the report named "education - wealthy in which" to UNESCO, which put forward four pillars concept: 21st century education should be organized around four learning, that is learning to know, learning to work, learn to cooperate, learn to survive. This shows learning will become the way to realize oneself [1]. On the June 8, 2001, the Ministry of Education has issued a "Basic Education Curriculum Reform" (Trial), the document states: To advocate the learning methods which students to actively participate, inquiry, discovery, exchanges and cooperation, focusing on the student experience and interest in learning, changes the phenomenon in curriculum implementation process, includes over-reliance on textbooks, too much emphasis on accepting learning, rote, mechanical training and others [2]. This curriculum reform advocates independence, exploration and cooperation, and gradually promotes the development of students' innovative consciousness and ability. Therefore, the importance of cognitive and learning to cooperation has become the main objective of the 21st century personnel training.

At present, China's higher education affected by long-term exam is still too much emphasis on screening and selection, lacks co-awareness and ability to get along with people, students gradually formed a distorted sense of competition and the self-serving behavior. At the same time, because the traditional learning model results in the loss of students' interest in learning, lacks student's awareness of innovation and capabilities. Therefore, the reform and development of educational teaching urgently need educational philosophy to reflect the characteristics of the times and diverse teaching mode to adapt the requirements of the times, thus ensuring the progressiveness, scientific and era of teaching, to achieve saving and efficient teaching results.

\section{PE Teaching Model Overview}

PE teaching model is a teaching program to reflect some teaching ideas, which includes a relatively stable structure of the teaching process and the corresponding teaching methodology, mainly in the design of teaching unit and teaching lessons [3]. Sport teaching mode includes a variety of modes: skills mastered teaching mode, the "target learning" teaching mode in happy sport, small group teaching mode, discovery teaching mode, and cooperative learning teaching model, discovery teaching model, successful teaching mode and others. 
Cooperative learning style sports teaching mode is that teacher according to differences in student learning levels, abilities, personality and other aspects into several heterogeneous learning groups in the classroom, assesses the team scores; in teaching by promoting the full exchange between teachers and students to enhance students' motivation in learning, achieved the effective teaching model which includes blending love to know, active classroom atmosphere, to improving the quality and effect [4]. Discovery sports teaching mode refers to the development of students' creative thinking as the goal to improve the ability of students to solve problems, promote students to acquire new knowledge and problem-solving experiences by their selves, mastery learning and thinking method as the main objective, mainly follow cognitive rules to consider in sports teaching. Successful PE teaching model is a model which uses sports methods and organizational measures, so that each student to establish individual goals, through appropriate assessment and their own efforts, to experience a sense of movement, to achieve a their own satisfactory effect.

\section{Current Situation of China's Traditional Aerobics Teaching Mode}

Aerobics is a sport which loved by the masses, the popularity of strong, set the gymnastics, dance, music, fitness, sports and entertainment in one [5]. For a long time by the shackles of the traditional "teachers teach, students learn" teaching mode, mostly mastered sports ability, trend to strong specialized, poor inflexible, narrow range of knowledge, lack of training capacity [6]. Fig. 1 show that college sports teachers in the classroom through skills explanation, demonstration of various combinations of movements and routines teach aerobics athletic skills, and organize students to arrange various practice forms of proficiency, meanwhile interspersed with correcting the error action. Students through imitation, grouping, consolidation and other forms exercise aerobics routines.

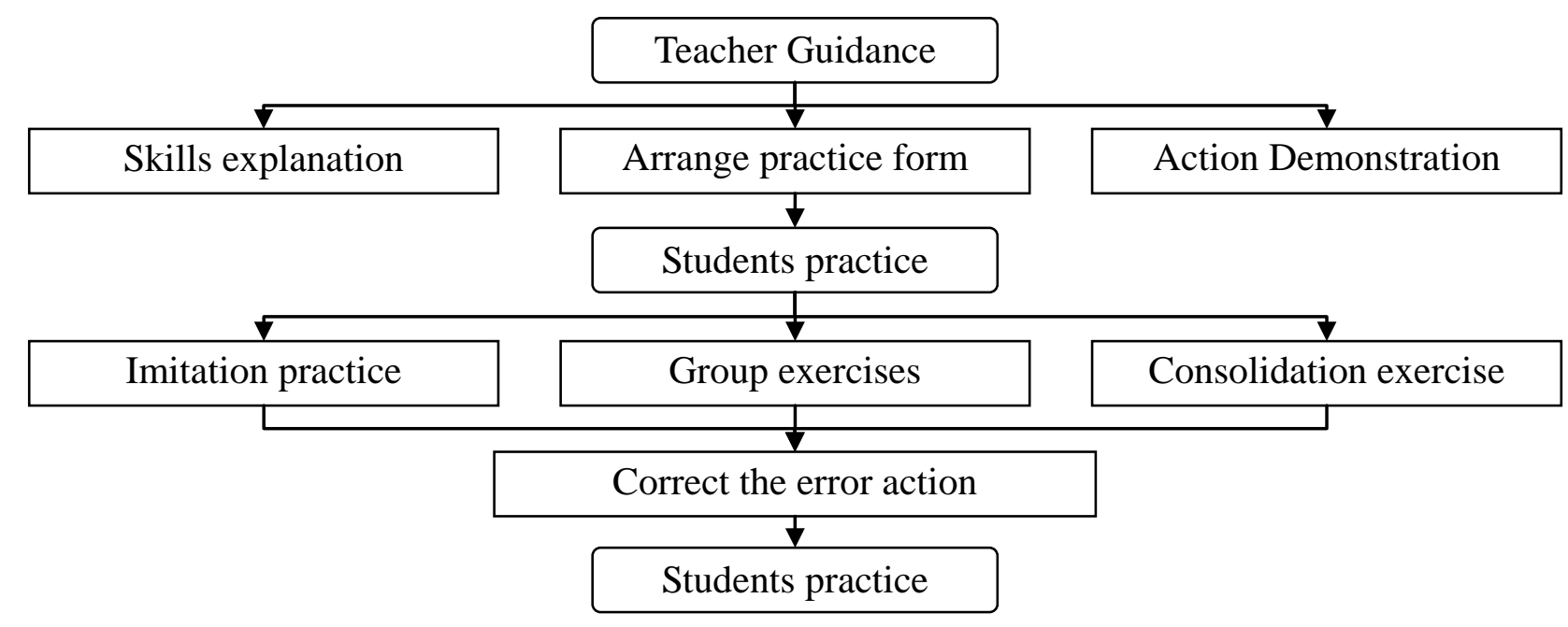

Fig. 1. Aerobics traditional teaching model flowchart

Thus, the traditional aerobics teaching model overemphasis teachers' "teaching", while ignoring students' "learning", seriously stifle students' interest in learning, reducing the motivation to learn physical education students, hindering the increasing of aerobics teaching quality, affecting the effectiveness of college aerobics teaching. Therefore, in order to cultivate high-quality, multi-knowledge, and strong creative talents, build a students' active participation, two-way interaction between teachers and students, training teaching mode with innovation and practical ability of students, need to create a new type of integrated multi-dimensional teaching mode. This paper studies cooperative learning mode, discovery teaching mode, successful teaching model, meanwhile introducing in colleges aerobics teaching, to build a new three-dimensional teaching model on the basis of theoretical research. In order to resolve the emotional shackles of traditional teaching on students training and creative thinking, so as to nurture and develop students' cooperation and competition, ability to adapt to society, and to provide reference for further carrying new teaching model in our college aerobics courses. 


\section{Significance of Creating Three-dimensional Teaching Model}

This study advocates creating three-dimensional teaching model in college aerobics teaching, organic combine with cooperative learning model, discovery teaching mode and successful teaching model. On the basis of cooperative learning model different grouping, learning techniques and theoretical knowledge aerobics movement through discovery teaching mode, and content innovation practice, finally among group, the group members follow the evaluation system of successful teaching model to evaluate outcome. Three modes depend on each other, complement each other to form a new multi-functional teaching model, and in which cooperative learning is a prerequisite, discovery teaching is a process, successful teaching is the result. The form "cooperation - discovery - successful" three-dimensional teaching model is a new breakthrough and new developments of teaching model, to fill the gaps in college aerobics teaching mode. It will fully mobilize teachers and students thinking, comprehensive improve students' interest in learning aerobics; it effectively integrate the teaching resources and can improve the quality of teaching; It is an innovative teaching model, can lead to students novelty and pride, for students innovation lay a solid foundation; it is a new trying to teaching methods and find a shortcut for teaching improvement and innovation.

\section{Construction of Three-dimensional Teaching Model in College Aerobics Courses}

Construction of "cooperation - discovery - successful" three-dimensional teaching model covers the theoretical basis; achieve goal, the program flow, implementation strategies, evaluation system and the corresponding countermeasures and suggestions, it is shown in Fig. 2. The Forming of three-dimensional aerobics teaching mode consists of "teaching process structure and teaching method type" framework.

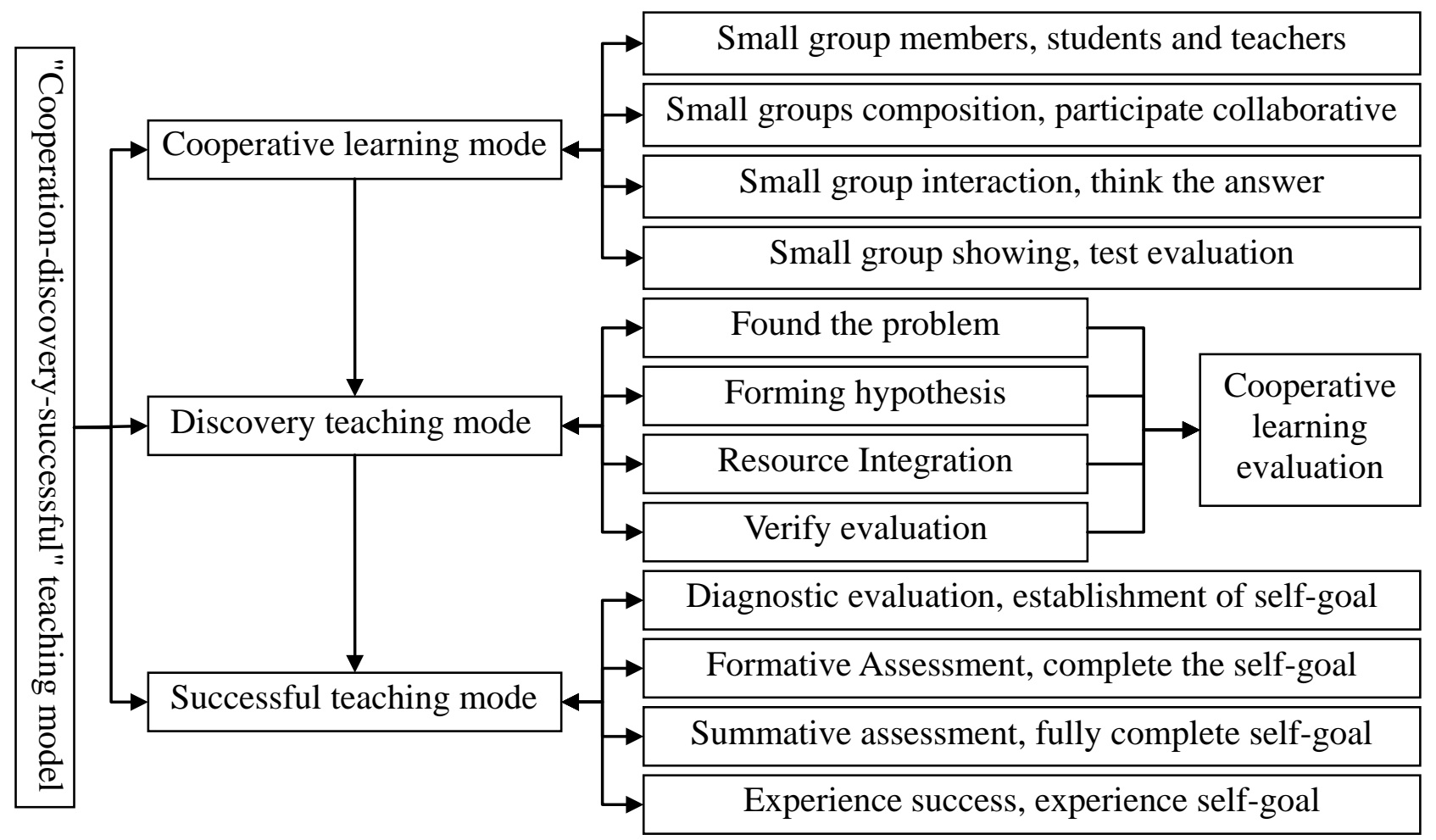

Fig. 2. "Cooperation - discovery - success" teaching model construction diagram

(1) Construction of cooperative learning model (learn to cooperate). The pattern consists of "Teacher provides claim - a small group composition - small group learning - a small group interaction - small group show". Cooperative teaching by grouping and a variety of evaluation forms fully developed competition between groups and cooperation within the group, active classroom atmosphere enhanced lateral contact between students and improve student learning consciousness, initiative, and help cultivate students' comprehensive ability. 
(2) Discovery teaching mode (learning to know). Discovery teaching mode composed with "found the problem - form a hypothesis - resources integration - verification assessment", and promoted students fully play and use their wisdom and ability to promote the mastery and understanding of aerobics technology action for student. Students use multimedia, image, social practice and other channels to learn basics knowledge, fitness principles and methods and so on [7], and to deepen students' understanding for aerobics. Meanwhile guides student self-investment, experience success, adjust and improve the students' negative perception and thinking.

(3) Successful teaching model (learn to evaluate). The pattern consists of "diagnostic evaluation formative evaluation - summative assessment - experience success". Successful teaching pattern is a sport teaching mode which uses sport means and organizational measures, so that each student establish individual goals, through their own efforts to achieve self-satisfied results, and thus obtain the successful satisfaction, and promote student's physical and mental development [8]. In the process of aerobics teaching teacher help students set up a self-goal, achieve satisfactory results, produce the joy of success and happiness emotions, and train lifelong habit of physical exercise.

\section{Conclusion}

this study under the four pillars theoretical guidance of the education in the 21st century, to explore and construct a scientific and rational aerobics teaching mode, contribute to achieve the educational goal which cultures students as "learning to know, learning to do, learning to cooperate, learn to survive" new era talents. "Cooperation - discovery - successful" three-dimensional teaching model advocated the formation of aerobics homogeneous group, cooperative learning, and promote discovery learning, achieve experiential successful learning, promote student has been significantly improved in knowledge, emotions, skills three areas. For fully deepening the reform of university aerobics teaching, expanding teaching practice space, and improving student movement skills and social adaptability has a significant effect.

\section{Acknowledgement}

This work is supported by 2009 research of teaching reform project of the education department of Liaoning province (11492092644), 2013 Bohai university research of teaching reform project (JG13QN017).

\section{References}

[1] UNESCO headquarters, "Learning: The Treasure within," Bei Jing, Education Science Press, 1996.

[2] Baidu Baike, "namespace," http://baike.baidu.com/view/1265891.htm?fr=aladdin, 2014-10-8.

[3] Z. M. Mao. "Sports Teaching Theory," Bei Jing, Higher Education Press, 2012.

[4] Q. P. Gao, "Application of Cooperative Teaching Model in College Public Aerobics Course," Bulletin of Sport Science and Technology, vol. 22, no. 3, pp. 37-38, 2014.

[5] Baidu Baike, "namespace," http://baike.baidu.com/view/105086.htm?fr=aladdin, 2014-10-8.

[6] Q. Li, X. J. Dong, "Construction and Implementation of the Curriculum Teaching Pattern of Aerobics in University," Journal of Guangzhou Sport University, vol. 27, no. 1, pp. 124-126, 2008.

[7] L. Zhong, "The Experimental Research on the Model of Inquiry Teaching of Body Building Exercise," Journal of Chengdu Physical Education Institute, vol. 30, no. 2, pp. 95-96, 2004.

[8] H. Y. Qian, "The Successful Physical Teaching Mode in Aerobics Course," Journal of Shanghai Physical Education Institute, vol. 25, no. 5, pp. 238-239, 2001. 